\title{
Altered Activities of Antioxidant Enzymes in Patients with Metabolic Syndrome
}

\author{
Lucie Vávrová Jana Kodydková Miroslav Zeman Magdaléna Dušejovská \\ Jaroslav Macášek Barbora Staňková Eva Tvrzická Aleš Žák
}

4th Department of Internal Medicine, First Faculty of Medicine, Charles University, and General Teaching Hospital, Prague, Czech Republic

\author{
Key Words \\ Metabolic syndrome $\cdot$ Antioxidant enzymes $\cdot$ Reduced glutathione $\cdot$ Conjugated dienes
}

\begin{abstract}
Objective: In the pathogenesis of the metabolic syndrome (MetS), an increase of oxidative stress could play an important role which is closely linked with insulin resistance, endothelial dysfunction, and chronic inflammation. The aim of our study was to assess several parameters of the antioxidant status in MetS. Methods: 40 subjects with MetS and 40 age- and sexmatched volunteers without MetS were examined for activities of superoxide dismutase (CuZnSOD), catalase (CAT), glutathione peroxidase 1 (GPX1), glutathione reductase (GR), paraoxonase1 (PON1), concentrations of reduced glutathione (GSH), and conjugated dienes in low-density lipoprotein (CD-LDL). Results: Subjects with MetS had higher activities of CuZnSOD $(p<0.05)$ and GR $(p<0.001)$, higher concentrations of CD-LDL $(p<0.001)$, lower activities of CAT $(p<0.05)$ and PON1 ( $<0.05)$, and lower concentrations of GSH $(p<0.05)$, as compared with controls. Activity of GPX1 was not significantly changed. Conclusions: Our results implicated an increased oxidative stress in MetS and a decreased antioxidative defense that correlated with some laboratory (triglycerides, high-density lipoprotein cholesterol (HDLC)) and clinical (waist circumference, blood pressure) components of MetS.
\end{abstract}


Vávrová et al.: Altered Activities of Antioxidant Enzymes in Patients with Metabolic Syndrome

\section{Introduction}

Currently, the prevailing notion of the metabolic syndrome (MetS) is that it is characterized by a cluster of risk factors for atherosclerosis and type 2 diabetes mellitus and can be regarded as a physiological and clinical entity [1]. The main components of MetS are accumulation of intra-abdominal fat, impaired metabolism of glucose, atherogenic dyslipidemia (low high-density lipoprotein cholesterol (HDL-C), hypertriglyceridemia), and arterial hypertension. In pathogenesis, several mechanisms were shown to take part, namely insulin resistance, chronic low-grade inflammation, endothelial dysfunction, and oxidative stress; their interactions have not been fully elucidated at present. Elevated levels of oxidative stress in subjects with MetS were demonstrated in many experimental and clinical studies $[2]$.

Oxidative stress is defined as an imbalance between the production of reactive oxygen and nitrogen species (RONS) and their insufficient decomposition by the antioxidant system which results in macromolecular damage and disruption of redox signaling and control [3]. Free radicals and non-radical oxidants belong to RONS. Free radicals could induce DNA mutations, structural disorders in proteins, and peroxidative damage of cell membrane and plasma lipids [4]. RONS play an important role in the pathogenesis of many cardiovascular and neurodegenerative diseases as well as in type 2 diabetes mellitus and its complications [5].

The defense mechanisms of the human body against oxidative stress are complex and involve cellular and extracellular antioxidant systems which are regulated at multiple levels [6]. Various enzymes, e.g. superoxide dismutase (CuZnSOD), glutathione peroxidase 1 (GPX1), catalase (CAT), paraoxonase 1 (PON1), glutathione reductase (GR), as well as nonenzymatic antioxidant compounds (e.g. metal chelators, low-molecular-weight antioxidants) take part in the antioxidant defense.

In the first step of the defense mechanism against superoxide anions $\left(\mathrm{O}_{2}{ }^{-}\right)$, the enzyme CuZnSOD catalyzes their dismutation into oxygen and $\mathrm{H}_{2} \mathrm{O}_{2}$. In the second step, CAT and GPX1 independently convert $\mathrm{H}_{2} \mathrm{O}_{2}$ to water. Any increase in the $\mathrm{CuZnSOD}$ catalytic activity produces an excess of $\mathrm{H}_{2} \mathrm{O}_{2}$ that must be efficiently neutralized by either CAT or GPX1; otherwise, $\mathrm{H}_{2} \mathrm{O}_{2}$ reacts with $\mathrm{O}_{2}{ }^{-}$producing in a two-step reaction (the Haber-Weiss reaction) hydroxyl radicals $\mathrm{OH}$ which are even more dangerous [5]. Cytosolic GPX1 detoxifies $\mathrm{H}_{2} \mathrm{O}_{2}$ in the presence of reduced glutathione (GSH), which is oxidized to oxidized glutathione (GSSG) and subsequently recycled by GR. GPX1 with the aid of GSH protects lipids against peroxidation. The pool of GSH has to be replenished by de novo synthesis that is catalyzed by the enzyme glutamate-cystein ligase. The PON1 enzyme as HDL-associated enzyme is implicated in the anti-inflammatory and antioxidant activities of HDL and impedes oxidative modification of low-density lipoprotein (LDL) thus protecting cell membranes from the damage caused by products of lipoperoxidation [7].

This study is focused on the state of the antioxidant defense system in patients with MetS. We intend to investigate the wide variety of known antioxidants in association with MetS. The activities of several antioxidant enzymes as well as the concentration of GSH were determined in the erythrocytes. It has been noted that these cells maintain fairly constant concentrations of enzymes throughout the life span which had been synthesized during the maturation of erythroid precursors [8]. Furthermore, levels of albumin, bilirubin, and calculated total peroxyl radical trapping (cTRAP) were assessed in serum. As a global marker of systemic oxidative stress, conjugated dienes in precipitated low-density lipoproteins (CD-LDL) were determined. 
Vávrová et al.: Altered Activities of Antioxidant Enzymes in Patients with Metabolic Syndrome

\section{Participants and Methods}

\section{Participants}

40 Caucasian subjects with MetS (20 male / 20 female) were recruited from outpatients who had been subsequently examined (from January 2008 until August 2010) at the Lipid Clinic of the 4th Department of Medicine, First Faculty of Medicine, Charles University in Prague. This study group was compared with a control group constituted from 40 volunteers without MetS matched for sex and age (20 male / 20 female), all Caucasian.

MetS was diagnosed according to the International Diabetes Federation criteria [9]. To be included, patients had to have central obesity (waist circumference $\geq 94 \mathrm{~cm}$ for men and $\geq 80 \mathrm{~cm}$ for women) and fulfill any two of the following four criteria: i) raised TG level ( $\geq 1.7 \mathrm{mmol} / \mathrm{l})$, ii) reduced HDL-C ( $<1.03 \mathrm{mmol} / \mathrm{l}$ in males and $<1.29 \mathrm{mmol} / \mathrm{l}$ in females) or specific treatment for these abnormalities, iii) raised blood pressure (BP) with systolic BP $\geq 130$ or diastolic BP $\geq 85 \mathrm{~mm} \mathrm{Hg}$ or treatment of previously diagnosed hypertension, and iv) raised fasting plasma glucose $(\geq 5.6 \mathrm{mmol} / \mathrm{l})$ or previously diagnosed type 2 diabetes mellitus. All samples were marked with unique anonymized identification numbers, and the data was merged only after the assays had been completed.

In the MetS group, 21 patients (52.5\%) had three, 13 patients (32.5\%) four, and 6 patients (15.0\%) had all five of the above mentioned components of MetS. In the control group, only three subjects (7.5\%) met two components of MetS, 15 (37.5\%) controls met one, and the 22 (55.0\%) volunteers showed no components of MetS. In the MetS group, 35 patients suffered from hypertension, and of these patients, 21 were under antihypertensive treatment. Among them, 12 were treated with an angiotensin converting enzyme (ACE) inhibitor or angiotensin receptor type 1 blockers, and the 9 remaining subjects were on a combination of ACE inhibitor with calcium channel blockers.

Exclusion criteria for both groups were the following: current antioxidant therapy, excessive alcohol consumption ( $>30 \mathrm{~g} /$ day), hormonal replacement therapy, supplementation with polyunsaturated fatty acids, manifestation of cardiovascular and/or cerebrovascular diseases, type 1 diabetes mellitus, liver (with exception of nonalcoholic fatty liver disease) and kidney diseases (creatinine $>130 \mu \mathrm{mol} / \mathrm{l}$ ), microalbuminuria (urinary albumine $30-300 \mathrm{mg} /$ day), hypothyroidism as well as recent infections and malignancies.

Informed consent was obtained from all participants. The study protocol was approved by the Ethical Committee of the First Faculty of Medicine, Charles University in Prague.

\section{Blood Samples}

Blood samples were collected after a 12-hour overnight fast. Activities of antioxidant enzymes (with exception of PON1) and concentrations of GSH were measured in hemolysed erythrocytes which had been separated from the EDTA plasma and washed three times with saline. Serum was used for all other parameters. Samples were stored at $-80^{\circ} \mathrm{C}$ until the assay.

\section{Methods}

Activities of antioxidant enzymes were measured spectrophotometrically using kinetic methods previously described [10]. Briefly, the activity of GPX1 was measured using tert-butyl hydroperoxide as a substrate, and the rate of NADPH degradation was monitored. The molar extinction coefficient of NADPH $(6,220$ $\mathrm{mol} / \mathrm{l} / \mathrm{cm}$ ) was used for calculation of activity which was then expressed as U/g hemoglobin. The activity of GR was measured by monitoring the rate of NADPH degradation. Activity was calculated using the molar extinction coefficient of NADPH and expressed as U/g hemoglobin. The CAT activity was calculated using the molar extinction coefficient of $\mathrm{H}_{2} \mathrm{O}_{2}(43.6 \mathrm{~mol} / \mathrm{l} / \mathrm{cm})$, whose degradation rate was monitored at $240 \mathrm{~nm}$. Activity is expressed as kU/g hemoglobin. The method of CuZnSOD activity assessment is based on the monitoring of the rate of NBT-formazan generation. Superoxide dismutase activity was calculated by means of a calibrating curve; superoxide dismutase standard (Cat. No. S9636-1kU) was purchased from Sigma Aldrich (St. Louis, MO, USA). Activity was expressed as U/g hemoglobin. The arylesterase activity of PON1 was measured using phenylacetate as a substrate. Arylesterase activity of PON1 was calculated using the molar extinction coefficient of the produced phenol $(1,310 \mathrm{~mol} / \mathrm{l} / \mathrm{cm})$ and expressed as $\mathrm{U} / \mathrm{ml}$ serum.

GSH was assessed by the modified spectrophotometric method according to Griffith [11]; this method is based on the determination of the relatively stable product of the reduction of 5,5' dithiobis-2-nitrobenzoic acid (DTNB). The concentration of CD-LDL was assessed by the modified method of Wieland and Seidel at $234 \mathrm{~nm}$ [12]; both methods have been fully described in the previously mentioned paper [10]. 
Vávrová et al.: Altered Activities of Antioxidant Enzymes in Patients with Metabolic Syndrome

All routine clinical tests were performed at the Institute for Clinical Biochemistry and Laboratory Diagnostics of General University Hospital in Prague: C-reactive protein (CRP) was determined by an immunoturbidimetric method using a K-ASSAY CRP kit (Kamiya Biomedical Company, Seattle, WA, USA; cv = max. 7.6\%) on a Hitachi Modular analyzer (Tokyo, Japan). Copper and zinc were measured using atomic absorption spectrometry, uric acid by an enzymatic colorimetric method with the uricase-peroxidase system, and bilirubin by the 2,5-dichlorophenyldiazonium method with a Hitachi Modular analyzer. Plasma albumin was assessed by a colorimetric method using bromocresol green. Plasma concentrations of total cholesterol (TC) and triglycerides (TG) were measured by enzymatic-colorimetric methods (Boehringer, Mannheim, Germany). HDL-C was determined in the supernatant after precipitation of lipoproteins B by PTA $/ \mathrm{Mg}^{2+}$, using the kit from the same manufacturer; LDL-C was calculated according to Friedewald's formula. Concentrations of apolipoproteins apo B and apo A1 were measured by the Laurell rocket electroimmunoassay using standard and specific antibodies (Behringwerke, Marburg, Germany). The concentrations of insulin and C-peptide were determined with an electrochemiluminescence immunoassay (Roche, Basel, Switzerland). The homeostasis model assessment of insulin resistance (HOMA-IR) index was calculated as HOMA-IR = (fasting serum glucose $(\mathrm{mmol} / \mathrm{l}) \times$ fasting serum insulin $(\mu \mathrm{U} / \mathrm{ml})) / 22.5$ [13]. The TRAP was calculated according to the formula: $(0.63$ (albumin) +1.02 (uric acid) +1.50 (bilirubin) [14]

\section{Statistical Analysis}

Data was expressed as mean and standard deviation or median (25th-75th percentile) for data different from normal distribution. Normality of the distribution was tested by the Shapiro-Wilks W test. Comparisons between the groups were carried out by the independent t-test. Mann-Whitney U test was used for nonparametric comparisons and Spearman correlation coefficients for correlation analyses. All analyses were performed using version 8.0 of StatSoft Statistica software (2007, Czech version). The p value $<0.05$ was considered statistically significant.

\section{Results}

Clinical and biochemical characteristics of the group of subjects with MetS and that of healthy controls are shown in table 1 . The groups did not differ in age. In both groups there were no subjects with either type 1 or type 2 diabetes mellitus. The subjects included in the MetS group suffer from insulin resistance when the metabolism of glucose was impaired.

As expected, subjects with MetS had significantly higher values of body mass index and waist circumference. They also had higher values of systolic BP and diastolic BP, glucose, TC, TG, apolipoprotein B (apo B), and uric acid as well as a higher level of insulin and insulin resistance, as assessed by the homeostatic model HOMA-IR. Decreased values were observed for plasma concentrations of HDL-C and apo A1. The difference in CRP did not reach statistical significance. As expected, men have decreased levels of HDL-C and $\mathrm{Cu}$ and increased values of waist circumference compared to women.

Activities of antioxidant enzymes and concentrations of GSH and CD-LDL together with levels of cTRAP are presented in table 2. In the group of subjects with MetS, activities of CuZnSOD and GR as well as concentrations of CD-LDL and levels of cTRAP were significantly elevated. On the other hand, activities of CAT and PON1 as well as concentrations of GSH were found to be decreased.

Spearmen correlations (after Bonferroni adjustment) between selected variables are shown in table 3. All risk factors of MetS correlated significantly with the number of components of MetS, namely abnormal levels of glucose, waist circumference, TG, HDL-C, and SBP. Concentrations of CD-LDL significantly correlated with concentrations of TG and HDL-C.

Activities of CuZnSOD correlated positively with those of GR ( $\mathrm{r}=0.341, \mathrm{p}<0.01)$ and GPX1 ( $r=0.260, p<0.05)$, and with concentrations of $\mathrm{Zn}(\mathrm{r}=0.363, \mathrm{p}<0.01)$ as well as negatively with the ratio $\mathrm{Cu} / \mathrm{Zn}(\mathrm{r}=-0.278, \mathrm{p}<0.05)$. Activities of PON1 correlated positively with 
Vávrová et al.: Altered Activities of Antioxidant Enzymes in Patients with Metabolic Syndrome

Table 1. Clinical and biochemical characteristics of subjects with the metabolic syndrome and of healthy controls ${ }^{a}$

\begin{tabular}{|c|c|c|c|c|c|c|}
\hline & \multicolumn{3}{|l|}{ Metabolic syndrome } & \multicolumn{3}{|l|}{ Controls } \\
\hline & all & M & $\mathrm{F}$ & all & M & $\mathrm{F}$ \\
\hline $\mathrm{N}$ & 40 & 20 & 20 & 40 & 20 & 20 \\
\hline Age, years & $\begin{array}{l}58.4 \\
(53.4-62.2)\end{array}$ & $\begin{array}{l}57.0 \\
(50.1-63.1)\end{array}$ & $\begin{array}{l}58.7 \\
(55.9-61.6)\end{array}$ & $\begin{array}{l}58.5 \\
(52.6-64.5)\end{array}$ & $\begin{array}{l}57.8 \\
(50.1-64.0)\end{array}$ & $\begin{array}{l}59.5 \\
(54.0-65.0)\end{array}$ \\
\hline Waist, cm & $101.4 \pm 9.1^{* * *}$ & $104.4 \pm 6.4^{* * *+}$ & $98.3 \pm 10.5^{* * *}$ & $82.5 \pm 11.0$ & $86.9 \pm 13.2^{+}$ & $78.3 \pm 6.6$ \\
\hline BMI, kg/m² & $\begin{array}{l}29.4 \\
(27.4-31.7)^{* * *}\end{array}$ & $\begin{array}{l}29.0 \\
(27.7-30.3)^{* *}\end{array}$ & $\begin{array}{l}30.6 \\
(25.9-32.4)^{* * *}\end{array}$ & $\begin{array}{l}23.9 \\
(21.9-25.5)\end{array}$ & $\begin{array}{l}25.0 \\
(21.8-26.3)\end{array}$ & $\begin{array}{l}23.8 \\
(21.9-25.4)\end{array}$ \\
\hline Smoking, N (\%) & $10(25.0)$ & $6(30.0)$ & $4(20.0)$ & $4(10.0)$ & $0(0.0)$ & $4(20.0)$ \\
\hline Hypertension, N (\%) & $35(87.5)$ & $18(90.0)$ & $17(85.0)$ & $8(20.0)$ & $5(25.0)$ & $3(15.0)$ \\
\hline Systolic BP, mm Hg & $\begin{array}{l}140 \\
(130-143)^{* *}\end{array}$ & $\begin{array}{l}140 \\
(130-140)^{* * *}\end{array}$ & $\begin{array}{l}140 \\
(130-145)\end{array}$ & $\begin{array}{l}130 \\
(120-130)\end{array}$ & $\begin{array}{l}128 \\
(120-130)\end{array}$ & $\begin{array}{l}130 \\
(120-140)\end{array}$ \\
\hline Diastolic BP, mm Hg & $90(88-95)^{* * *}$ & $90(90-95)^{* * *}$ & $90(83-95)^{* * *}$ & $80(80-80)$ & $80(80-85)$ & $80(80-85)$ \\
\hline Glucose, mmol/l & $5.4(4.8-6.1)^{* * *}$ & $5.0(4.7-5.8)$ & $5.6(5.1-6.3)^{* *}$ & $4.7(4.5-5.1)$ & $4.9(4.5-5.4)$ & $4.7(4.3-5.0)$ \\
\hline Insulin, mU/l & $11.4(8.7-14.8)^{* * *}$ & * $11.4(8.6-15.1)^{*}$ & $11.3(9.4-14.3)^{*}$ & $7.8(4.6-9.5)$ & $8.5(4.8-10.1)$ & $7.6(4.6-9.1)$ \\
\hline C-peptid, nmol/l & $\begin{array}{l}0.97 \\
(0.84-1.19)^{* * *}\end{array}$ & $\begin{array}{l}0.99 \\
(0.86-1.14)^{* * *}\end{array}$ & $\begin{array}{l}0.93 \\
(0.81-1.28)^{* * *}\end{array}$ & $\begin{array}{l}0.64 \\
(0.51-0.75)\end{array}$ & $\begin{array}{l}0.59 \\
(0.46-0.75)\end{array}$ & $\begin{array}{l}0.68 \\
(0.55-0.73)\end{array}$ \\
\hline HOMA-IR & $3.0(1.9-3.8)^{* * *}$ & $3.0(1.8-3.7)^{*}$ & $3.0(2.1-4.5)^{* *}$ & $1.6(1.0-2.1)$ & $1.8(1.0-2.2)$ & $1.6(1.0-1.9)$ \\
\hline TC, mmol/l & $6.3(5.2-7.3)^{*}$ & $6.2(5.2-7.1)^{*}$ & $6.5(5.2-7.4)$ & $5.7(5.0-6.2)$ & $5.7(4.8-6.1)$ & $5.8(5.0-6.6)$ \\
\hline $\mathrm{TG}, \mathrm{mmol} / \mathrm{l}$ & $2.6(1.9-3.7)^{* * *}$ & $2.3(1.9-3.6)^{* *}$ & $2.7(1.7-3.9)^{* * *}$ & $1.1(0.9-1.4)$ & $1.1(0.8-1.4)$ & $1.0(0.9-1.3)$ \\
\hline HDL-C, mmol/l & $1.2(1.1-1.3)^{* * *}$ & $1.1(1.0-1.2)^{* * *+}$ & $1.2(1.1-1.3)^{* * *}$ & $1.6(1.3-1.8)$ & $1.5(1.3-1.8)$ & $1.6(1.5-1.9)$ \\
\hline LDL-C, mmol/l & $3.6(3.1-4.3)$ & $3.5(3.2-4.2)$ & $3.6(3.0-4.3)$ & $3.5(2.8-4.3)$ & $3.4(2.9-3.8)$ & $3.6(2.8-4.3)$ \\
\hline Apo A1, g/l & $1.26 \pm 0.25^{* *}$ & $1.24 \pm 0.25$ & $1.28 \pm 0.26^{* *}$ & $1.43 \pm 0.21$ & $1.36 \pm 0.20+$ & $1.50 \pm 0.20$ \\
\hline Apo B, g/l & $1.34 \pm 0.32^{* * *}$ & $1.39 \pm 0.26^{* * *}$ & $1.28 \pm 0.37$ & $1.09 \pm 0.25$ & $1.06 \pm 0.22$ & $1.13 \pm 0.28$ \\
\hline NEFA, mmol/l & $\begin{array}{l}0.50 \\
(0.39-0.72)\end{array}$ & $\begin{array}{l}0.43 \\
(0.35-0.68)\end{array}$ & $\begin{array}{l}0.51 \\
(0.43-0.75)\end{array}$ & $\begin{array}{l}0.55 \\
(0.43-0.71)\end{array}$ & $\begin{array}{l}0.59 \\
(0.435-0.83)\end{array}$ & $\begin{array}{l}0.55 \\
(0.40-0.61)\end{array}$ \\
\hline CRP, mg/l & $2.7(2.0-6.3)$ & $2.8(2.0-4.3)$ & $2.7(2.0-7.4)$ & $2.3(2.0-6.5)$ & $2.0(2.0-4.3)$ & $4.6(2.1-7.3)$ \\
\hline $\mathrm{Cu}, \mu \mathrm{mol} / \mathrm{l}$ & $\begin{array}{l}17.7 \\
(16.0-20.5)\end{array}$ & $\begin{array}{l}17.0 \\
(15.5-18.4)\end{array}$ & $\begin{array}{l}19.6 \\
(16.3-21.7)\end{array}$ & $\begin{array}{l}18.5 \\
(16.3-21.5)\end{array}$ & $\begin{array}{l}16.3 \\
(14.3-18.6)^{++}\end{array}$ & $\begin{array}{l}19.9 \\
(18.5-23.4)\end{array}$ \\
\hline $\mathrm{Zn}, \mu \mathrm{mol} / \mathrm{l}$ & $\begin{array}{l}16.0 \\
(13.4-17.7)\end{array}$ & $\begin{array}{l}15.8 \\
(13.4-17.8)\end{array}$ & $\begin{array}{l}16.3 \\
(13.8-17.1)\end{array}$ & $\begin{array}{l}15.4 \\
(14.6-19.9)\end{array}$ & $\begin{array}{l}16.0 \\
(14.5-18.3)\end{array}$ & $\begin{array}{l}15.2 \\
(14.7-20.8)\end{array}$ \\
\hline Bilirubin, $\mu \mathrm{mol} / \mathrm{l}$ & $\begin{array}{l}9.1 \\
(6.8-12.9)\end{array}$ & $\begin{array}{l}10.9 \\
(7.9-13.8)+\end{array}$ & $\begin{array}{l}7.2 \\
(6.1-9.6)\end{array}$ & $\begin{array}{l}10.6 \\
(8.0-15.2)\end{array}$ & $\begin{array}{l}13.9 \\
(9.8-18.2)^{++}\end{array}$ & $\begin{array}{l}9.0 \\
(7.5-12.3)\end{array}$ \\
\hline Uric acid, $\mu \mathrm{mol} / \mathrm{l}$ & $\begin{array}{l}346 \\
(290-390)^{* *}\end{array}$ & $\begin{array}{l}355 \\
(312-420)^{*}\end{array}$ & $\begin{array}{l}329 \\
(275-352)^{* *}\end{array}$ & $\begin{array}{l}293 \\
(236-346)\end{array}$ & $\begin{array}{l}320 \\
(291-370)^{+++}\end{array}$ & $\begin{array}{l}251 \\
(195-293)\end{array}$ \\
\hline
\end{tabular}

$\mathrm{BP}=$ Blood pressure; $\mathrm{TC}$ = total cholesterol; TG = triglycerides; HDL-C = high density lipoprotein; LDL-C = low density lipoprotein; Apo = apolipoprotein; HOMA-IR = homeostasis model assessment of insulin resistance; QUICKI = quantitative insulin sensitivity check index; NEFA = non-esterified fatty acids; CRP = C-reactive protein; Met = metabolic syndrome.

a Data presented as mean \pm standard deviation (SD) for parametric and median (IQR) for non-parametric variables;

MetS versus controls: ${ }^{*} \mathrm{p}<0.05,{ }^{* *} \mathrm{p}<0.01,{ }^{* * *} \mathrm{p}<0.001$. Female versus male: ${ }^{+} \mathrm{p}<0.05,{ }^{++} \mathrm{p}<0.01,{ }^{+++} \mathrm{p}<0.001$.

apo A1 ( $\mathrm{r}=0.479, \mathrm{p}<0.001)$. Concentrations of CD-LDL correlated positively with TC $(\mathrm{r}=$ 0.565 , $\mathrm{p}<0.001)$, apo B ( $\mathrm{r}=0.597$, $\mathrm{p}<0.001)$, and LDL-C $(\mathrm{r}=0.384, \mathrm{p}<0.001)$, and negatively with CAT $(r=-0.233, p<0.05)$.

\section{Discussion}

In this study, comparing MetS patients with an age- and sex-matched control group, increased activities of CuZnSOD (+15\%, p < 0.05) and GR (+19\%; p < 0.001) and increased levels of CD-LDL $(+14.4 \%$; $p<0.001)$ and cTRAP $(+6.5 \%$; $<0.01)$ were found in MetS 
Table 2. Parameters of oxidative stress of studied groups

\begin{tabular}{|c|c|c|c|c|c|c|}
\hline & \multicolumn{3}{|c|}{ Metabolic syndrome } & \multicolumn{3}{|l|}{ Controls } \\
\hline & all & M & $\mathrm{F}$ & all & M & $\mathrm{F}$ \\
\hline GPX1, U/g Hb & $59.4 \pm 15.8$ & $57.6 \pm 18.1$ & $61.1 \pm 13.4$ & $59.1 \pm 17.7$ & $55.4 \pm 19.2$ & $62.8 \pm 15.7$ \\
\hline GR, U/g Hb & $8.19 \pm 1.54^{* * *}$ & $8.74 \pm 1.21^{* * *+}$ & $7.63 \pm 1.67$ & $6.88 \pm 1.66$ & $6.92 \pm 1.76$ & $6.83 \pm 1.60$ \\
\hline \multirow[t]{2}{*}{ GSH, mg/g Hb } & 0.57 & 0.56 & 1.51 & 1.46 & 1.22 & 1.70 \\
\hline & $(0.38-2.73)^{*}$ & $(0.40-0.70)$ & $(0.38-5.01)$ & $(0.41-5.22)$ & $(0.43-5.40)$ & $(0.40-5.05)$ \\
\hline CAT, kU/g Hb & $189.6 \pm 31.8^{*}$ & $192.5 \pm 27.8$ & $186.7 \pm 35.8$ & $204.6 \pm 33.0$ & $206.1 \pm 32.5$ & $203.1 \pm 34.4$ \\
\hline CuZnSOD, kU/g Hb & $2.3(1.9-2.5)^{* *}$ & $2.3(2.2-2.5)^{*}$ & $2.0(1.7-2.5)^{+}$ & $2.0(1.2-2.5)$ & $2.2(1.1-2.6)$ & $2.0(1.3-2.4)$ \\
\hline PON1, kU/l & $158.9 \pm 41.9^{*}$ & $152.0 \pm 47.4$ & $165.7 \pm 35.4$ & $179.9 \pm 42.3$ & $170.2 \pm 36.1$ & $189.5 \pm 46.5$ \\
\hline \multirow[t]{2}{*}{$\mathrm{CD}, \mathrm{mmol} / \mathrm{l}$} & 61.9 & 57.3 & 63.8 & 54.1 & 53.3 & 57.5 \\
\hline & $(54.1-84.3)^{* * *}$ & $(53.4-68.7)^{*}$ & $(55.3-94.2)^{*}$ & $(41.3-63.6)$ & $(33.8-63.6)$ & $(42.9-68.1)$ \\
\hline \multirow[t]{2}{*}{ cTRAP, $\mu \mathrm{mol} / \mathrm{l}$} & 823 & 875 & 785 & 773 & 809 & 701 \\
\hline & $(766-877)^{* *}$ & $(816-909)^{*++}$ & $(732-835)^{* *}$ & $(691-820)$ & $(768-865)^{+++}$ & $(655-776)$ \\
\hline
\end{tabular}

GPX1 = glutathione peroxidase 1; GR = glutathione reductase; $\mathrm{GSH}=$ reduced glutathione; $\mathrm{CAT}=$ catalase; $\mathrm{CuZnSOD}=\mathrm{CuZn}-$ superoxide dismutase; PON1 = paraoxonase 1 - arylesterase activity; CD = conjugated dienes in precipitated LDL; cTRAP = calculated total peroxyl radical trapping - calculation: [0.63 (albumin) + 1.02 (uric acid) +1.50 (bilirubin)]; Met = metabolic syndrome; Data presented as mean \pm standard deviation (S.D.) for parametric and median (IQR) for non-parametric variables.

MetS versus controls: ${ }^{*} \mathrm{p}<0.05,{ }^{* *} \mathrm{p}<0.01,{ }^{* * *} \mathrm{p}<0.001$. Female versus male: ${ }^{+} \mathrm{p}<0.05,{ }^{++} \mathrm{p}<0.01,{ }^{+++} \mathrm{p}<0.001$.

Table 3. Spearman correlation coefficients for components of the metabolic syndrome and parameters of oxidative stress in the combined group (metabolic syndrome plus controls) ( $\mathrm{N}=80$ )

\begin{tabular}{lllllllllllllll}
\hline & SBP & TG & HDL-C & Glucose & HOMA-IR & MetSC & CD & PON1 & GR & GPX1 & CAT & CuZnSOD \\
\hline Waist & 0.313 & $0.533^{+++}$ & $-0.602^{+++}$ & $0.402^{++}$ & $0.570^{+++}$ & $0.717^{++}$ & 0.336 & -0.103 & $0.377^{+}$ & -0.160 & -0.115 & 0.049 \\
SBP & - & 0.270 & -0.147 & 0.141 & 0.103 & $0.405^{++}$ & 0.338 & -0.039 & 0.129 & 0.076 & -0.108 & -0.097 \\
TG & - & - & $-0.631^{+++}$ & $0.396^{+}$ & $0.453^{++}$ & $0.736^{+++}$ & $0.571^{+++}$ & -0.170 & 0.219 & -0.067 & -0.182 & 0.017 & \\
HDL-C & - & - & - & $-0.357^{+}$ & $-0.405^{+}$ & $-0.681^{+++}$ & $-0.374^{+}$ & 0.321 & -0.148 & 0.086 & 0.133 & -0.015 \\
Glucose & - & - & - & - & $0.555^{++}$ & $0.540^{+++}$ & 0.019 & -0.103 & 0.127 & -0.286 & -0.081 & -0.118 \\
HOMA-IR & - & - & - & - & - & $0.493^{+++}$ & 0.099 & -0.088 & 0.216 & 0.025 & -0.066 & -0.073 \\
MetSC & - & - & - & - & - & - & $0.442^{++}$ & -0.193 & 0.261 & -0.097 & -0.249 & -0.115 \\
\hline
\end{tabular}

SBP = Systolic blood pressure; TG = triglycerides; HDL-C = high density lipoprotein; HOMA-IR = homeostasis model assessment of insulin resistance; $\mathrm{Met}=$ metabolic syndrome; $\mathrm{MetSC}=$ number of components of the MetS $(\mathrm{N}=1-5$; waist circumference, glucose, triglycerides, HDL-C, SBP); GPX1 = glutathione peroxidase 1; GR = glutathione reductase; CAT = catalase; CuZnSOD = CuZn-superoxide dismutase; PON1 = paraoxonase-1-arylesterase activity; $\mathrm{CD}=$ conjugated dienes in precipitated LDL. ${ }^{+} \mathrm{p}<0.05 ;{ }^{++} \mathrm{p}<0.01 ;{ }^{+++} \mathrm{p}<0.001$; after Bonferroni adjustment.

patients. In contrast, activities of CAT $(-7.3 \% ; \mathrm{p}<0.05)$ and PON1 $(-11.7 \% ; \mathrm{p}<0.05)$ as well as serum concentration of GSH $(-61 \%$; $<<0.05)$ were significantly decreased. The HOMA-IR demonstrated evidence of a significantly increased insulin resistance in subjects with MetS.

Under resting physiological conditions, biologic systems generate only small amounts of the superoxide anion. Its overproduction can result from mitochondrial electron leakage in hyperglycemia [15]. Other causes of superoxide overproduction are increased activities of $\mathrm{NAD}(\mathrm{P}) \mathrm{H}$ oxidases [16], xanthine oxidase, lipoxygenase, and cyclooxygenase as well as an imbalance in the thioredoxin system [17]. Large amounts of superoxide and other RONS arise in the accumulated fat, mainly due to increased activities of NAD(P)H oxidases and a decreased expression of antioxidant enzymes [18]. Adipose tissue is an important generator of oxidative stress and inflammation, contributing to the production of pro-inflammatory cytokines 
Vávrová et al.: Altered Activities of Antioxidant Enzymes in Patients with Metabolic Syndrome

(TNF $\alpha$, IL-1, IL-6 etc.). Oxidative stress is supposed to worsen the inflammatory state in MetS via activation of redox-sensitive transcription factors (particularly NFKB) by RONS, inducing the expression of TNF $\alpha$ and IL-6. These cytokines increased CRP synthesis. However, in our study, we did not find a statistically significant difference in CRP levels between MetS patients and controls. This could be caused by the method used for CRP measurement. The method used in our study lacks the sensitivity to differ between low-grade inflammation in MetS (CRP between 1.0 and $3 \mathrm{mg} / \mathrm{l}$ ) and subjects without MetS (CRP $<1.0 \mathrm{mg} / \mathrm{l}$ ).

The raised CuZnSOD activities in the erythrocytes of patients with MetS found in our study may be compared with the results of Mitrijevic-Sreckovic et al. [19], who described slightly increased CuZnSOD activities in children with MetS in comparison with obese children without MetS. Studies on serum CuZnSOD activities did not show consistent results [20,21]. Increased CuZnSOD activity results in raised amounts of $\mathrm{H}_{2} \mathrm{O}_{2}$ which becomes toxic when activity of CAT is normal or decreased. Induction of one enzyme (CAT or CuZnSOD) does not necessarily lead to the induction of the other one [22]. Another source of $\mathrm{H}_{2} \mathrm{O}_{2}$ is its passage through the erythrocyte membrane [23]. The elevated production of ROS in the endothelium could thus lead to increased levels of ROS also in erythrocytes.

In our study, we have found a significantly decreased activity of CAT. Because of the increased activity of CuZnSOD in our study, elevated levels of $\mathrm{H}_{2} \mathrm{O}_{2}$ have to be expected. According to study of Kirkman et al. [24], during lengthy exposure of CAT to $\mathrm{H}_{2} \mathrm{O}_{2}$, the CAT-bound NADPH became oxidized to $\mathrm{NADP}^{+}$and activity of CAT fell to about one third of the initial activity. Consequently, the cause of the decrease of CAT activity could be the damage of erythrocyte CAT by $\mathrm{H}_{2} \mathrm{O}_{2}$. Contrary to our study, Cardona et al. $[20,21]$ found increased activities of CAT in patients with hypertriglyceridemia (concentration of TG $>1.7 \mathrm{mmol} / \mathrm{l}$ ) apart from the presence of MetS, and these activities were further increased after fat overload. Decreased activities of CAT were described in patients bearing only individual components of MetS - obesity [25], hypertension [26], or insulin resistance [27]. Decreased activity of CAT implies stressed condition of erythrocytes when complete removal of $\mathrm{H}_{2} \mathrm{O}_{2}$ is not possible [28]. Low activities of CAT were associated with an increased risk of diabetes mellitus and its complications [5, 29].

The GPX1 activity in our study was not altered in MetS patients. This result is in accordance with the study of Mitrijevic-Sreckovic [19]. On the contrary, Cardona et al. [20, 21] found lower activities of GPX1 in a group of subjects with hypertriglyceridemia, a part of MetS presence, and the drop of its activity was almost to $75 \%$ of that of the control group. Bougoulia et al. [30] showed decreased activity of GPX1 in obese subjects as well as an increase after weight reduction.

As expected, concentrations of GSH were significantly decreased and activities of GR increased in our group of subjects with MetS. Decreased concentrations of GSH with opposite changes in GSSG levels were also found in MetS subjects in the study of Cardona et al. [20]. On the other hand, Cardona et al. [21] registered a significant drop in GR activity in MetS subjects. Increased activity of GR could be attributed to a compensatory protective mechanism of the cells against ROS. Furthermore, our expected increase in the GSSG/GSH ratio due to lower levels of GSH may stimulate compensatory increase in GR activity in blood to reduce higher levels of GSSG into GSH [31].

The finding of decreased arylesterase activities of PON1 in our subjects with MetS is in accordance with other studies [32,33]. Because it was shown [34] that there is a strong positive correlation between arylesterase and paraoxonase activity of PON1, we could therefore discuss arylesterase and paraoxonase activity of PON1 together. Low activities of PON1 have been shown to be associated with oxidative stress, hypercholesterolemia, diabetes mellitus, cardiovascular diseases, and sepsis [34, 35].

In the present study, we found significantly higher concentrations of CD-LDL in subjects with MetS. This test was shown to be the most sensitive indicator of lipid peroxidation and can be regarded as a global marker of systemic oxidative stress [36]. In this study, several 
Vávrová et al.: Altered Activities of Antioxidant Enzymes in Patients with Metabolic Syndrome

anthropometric and biochemical characteristics of MetS correlated significantly with increased concentrations of CD-LDL, which reflect oxidation of the lipid component of LDL. This finding is in agreement with the results of our studies concerning the severity of MetS, oxidative stress, hypertriglyceridemia, and fatty acid metabolism $[37,38]$. The important role of lipid peroxidation in the pathogenesis of MetS has been proven in many experimental and clinical studies [39].

\section{Conclusion}

In the present study, we estimated a wide variety of antioxidant enzymes, and activities of several enzymes were changed in subjects with MetS. Enzyme activities were assessed in the erythrocytes where the concentration of enzymes remain stable throughout the life span and reflect adaptive changes in their expression in erythroid precursors. According to our results, alterations of antioxidant enzymes related to MetS are not uniform. While activities of CuZnSOD and GR were higher in the MetS group than in healthy subjects, a decrease in CAT and PON1 as well as the absence of the expected increase in GPX1 indicate a disorder in antioxidant defense mechanisms. Our results could be interpreted that the erythrocytes and their GSH levels and activities of GR and GPX1 protect against oxidative stress in MetS. The severity of MetS, as assessed by the number of its components, significantly correlated with the concentrations of CD-LDL.

\section{Acknowledgments}

This work was supported by by the Research Project of Charles University in Prague, First Faculty of Medicine - PRVOUK-P25/LF1/2, and by the grant IGA NS9769-4 of the Ministry of Health of the Czech Republic.

\section{Disclosure Statement}

We hereby state that there is no conflict of interest.

\section{References}

1 Grundy SM: Metabolic syndrome: a multiplex cardiovascular risk factor. J Clin Endocrinol Metabol 2007;92: 399-404.

2 Roberts CK, Sindhu KK: Oxidative stress and metabolic syndrome. Life Sci 2009;84:705-712.

- 3 Duracková Z: Some current insights into oxidative stress. Physiol Res 2010;59:459-469.

- 4 Valko M, Leibfritz D, Moncol J, Cronin MT, Mazur M, Telser J: Free radicals and antioxidants in normal physiological functions and human disease. Int J Biochem Cell Biol 2007;39:44-84.

5 Halliwell B, Gutteridge JMC: Free Radicals in Biology and Medicine, 4th ed. Oxford, Oxford University Press, 2008.

6 Surh YJ: Transcriptional regulation of cellular antioxidant defense mechanism; in Surh YJ, Packer L (eds): Oxidative Stress, Inflammation and Health. Boca Raton, CRC Press, 2005, pp21-40.

- 7 Soran H, Younis NN, Charlton-Menys V, Durrington P: Variation in paraoxonase-1 activity and atherosclerosis. Curr Opin Lipidol 2009;20:265-274.

- 8 Harris ED: Regulation of antioxidant enzymes. FASEB J 1992;6:2675-2683.

- 9 Alberti KG, Zimmet P, Shaw J: The metabolic syndrome - a new worldwide definition. Lancet 2005;366:10591062.

10 Kodydková J, Vávrová L, Zeman M, Jirák R, Macásek J, Stanková B, Tvrzická E, Zák A: Antioxidative enzymes and increased oxidative stress in depressive women. Clin Biochem 2009;42:1368-1374.

11 Griffith OW: Glutathione and glutathione disulphide; in Bergemeyer HU (ed): Methods of Enzymatic Analysis, Weinheim, VCH 1985, pp 521-529. 
Vávrová et al.: Altered Activities of Antioxidant Enzymes in Patients with Metabolic Syndrome

12 Wieland H, Seidel D: A simple specific method for precipitation of low density lipoproteins. J Lipid Res 1983; 24:904-909.

13 Vogeser M, König D, Frey I, Predel HG, Parhofer KG, Berg A: Fasting serum insulin and the homeostasis model of insulin resistance (HOMA-IR) in the monitoring of lifestyle interventions in obese persons. Clin Biochem 2007;40:964-968.

14 Roth E, Manhart N, Wessner B: Assessing the antioxidative status in critically ill patients. Curr Opin Clin Nutr Metab Care 2004;7:161-168.

15 Yamagishi SI, Edelstein D, Du XL, Brownlee M: Hyperglycemia potentiates collagen-induced platelet activation through mitochondrial superoxide overproduction. Diabetes 2001;50:1491-1494.

16 Paravicini TM, Touyz RM: NADPH oxidases, reactive oxygen species, and hypertension: clinical implications and therapeutic possibilities. Diabetes Care 2008;31:S170-S180.

17 Nordberg J, Arnér ES: Reactive oxygen species, antioxidants, and the mammalian thioredoxin system. Free Radic Biol Med 2001;31:1287-1312.

18 Furukawa S, Fujita T, Shimabukuro M, Iwaki M, Yamada Y, Nakajima Y, Nakayama O, Makishima M, Matsuda M, Shimomura I: Increased oxidative stress in obesity and its impact on metabolic syndrome. J Clin Invest 2004;114:1752-1761.

-19 Dimitrijevic-Sreckovic V, Colak E, Djordjevic P, Gostiljac D, Sreckovic B, Popovic S, Canovic F, Ilic M, Obrenovic R, Vukcevic V, Nikolic D, Nisic T, Milic G, Pejcic G: Prothrombogenic factors and reduced antioxidative defense in children and adolescents with pre-metabolic and metabolic syndrome. Clin Chem Lab Med 2007;45:1140-1144.

-20 Cardona F, Túnez I, Tasset I, Montilla P, Collantes E, Tinahones FJ: Fat overload aggravates oxidative stress in patients with the metabolic syndrome. Eur J Clin Invest 2008;38:510-515.

-21 Cardona F, Tunez I, Tasset I, Murri M, Tinahones FJ: Similar increase in oxidative stress after fat overload in persons with baseline hypertriglyceridaemia with or without the metabolic syndrome. Clin Biochem 2008;41: 701-705.

22 Amstad P, Peskin A, Shah G, Mirault ME, Moret R, Zbinden I, Cerutti P: The balance between Cu,Zn-superoxide dismutase and catalase affects the sensitivity of mouse epidermal cells to oxidative stress. Biochemistry 1991; 30:9305-9313.

23 Low FM, Hampton MB, Winterbourn CC: Peroxiredoxin 2 and peroxide metabolism in the erythrocyte. Antioxid Redox Signal 2008;10:1621-30.

24 Kirkman HN, Galiano S, Gaetani GF: The function of catalase-bound NADPH. J Biol Chem 1987;262:660-666.

25 Viroonudomphol D, Pongpaew P, Tungtrongchitr R, Phonrat B, Supawan V, Vudhivai N, Schelp FP: Erythrocyte antioxidant enzymes and blood pressure in relation to overweight and obese Thai in Bangkok. Southeast Asian J Trop Med Public Health 2000;31:325-334.

-26 Rodrigo R, Prat H, Passalacqua W, Araya J, Guichard C, Bächler JP: Relationship between oxidative stress and essential hypertension. Hypertens Res 2007;30:1159-1167.

27 Shin MJ, Park E: Contribution of insulin resistance to reduced antioxidant enzymes and vitamins in nonobese Korean children. Clin Chim Acta 2006;365:200-205.

-28 Nandeesha H, Sathiyapriya V, Bobby Z, Pavithran P, Agrawal A, Selvaraj N: Altered oxidant-antioxidant status in non-obese men with moderate essential hypertension. Indian J Med Sci 2007;61:326-331.

29 Chistiakov DA, Zotova EV, Savost'anov KV, Bursa TR, Galeev IV, Strokov IA, Nosikov VV: The 262T >C promoter polymorphism of the catalase gene is associated with diabetic neuropathy in type 1 diabetic Russian patients. Diabetes Metab 2006;32:63-68.

-30 Bougoulia M, Triantos A, Kolioakos G: Plasma interleukin-6 levels, glutathione peroxidase and isoprostane in obese women before and after weight loss. Association with cardiovascular risk factors. Hormones (Athens) 2006;5:192-199.

-31 Paşaoğlu H, Muhtaroğlu S, Güneş M, Utaş C. The role of the oxidative state of glutathione and glutathionerelated enzymes in anemia of hemodialysis patients. Clin Biochem1996:29:567-72.

-32 Garin MC, Kalix B, Morabia A, James RW: Small, dense lipoprotein particles and reduced paraoxonase-1 in patients with the metabolic syndrome. J Clin Endocrinol Metab 2005;90:2264-2269.

33 Rizos E, Tambaki AP, Gazi I, Tselepis AD, Elisaf M: Lipoprotein-associated PAF-acetylhydrolase activity in subjects with the metabolic syndrome. Prostaglandins Leukot Essent Fatty Acids 2005;72:203-209.

34 Novak F, Vavrova L, Kodydkova J, Novak F Sr, Hynkova M, Zak A, Novakova O: Decreased paraoxonase activity in critically ill patients with sepsis. Clin Exp Med 2010;10:21-25.

-35 Rosenblat M, Aviram M: Paraoxonases role in the prevention of cardiovascular diseases. Biofactors 2009;35: 98-104.

-36 Güzel S, Seven A, Satman I, Burçak G: Comparison of oxidative stress indicators in plasma of recent-onset and long-term type 1 diabetic patients. J Toxicol Environ Health A 2000;59:7-14.

-37 Zák A, Tvrzická E, Vecka M, Jáchymová M, Duffková L, Stanková B, Vávrová L, Kodydková J, Zeman M: Severity of metabolic syndrome unfavorably influences oxidative stress and fatty acid metabolism in men. Tohoku J Exp Med 2007;212:359-371.

-38 Zeman M, Zák A, Vecka M, Tvrzická E, Romaniv S, Konárková M: Treatment of hypertriglyceridaemia with fenofibrate, fatty acid composition of plasma and LDL, and their relations to parameters of lipoperoxidation of LDL. Ann N Y Acad Sci 2002;967:336-341.

-39 Holvoet P, Lee DH, Steffes M, Gross M, Jacobs DR Jr: Association between circulating oxidized low-density lipoprotein and incidence of the metabolic syndrome. JAMA 2008;299:2287-2293. 